\title{
DESIGN AND ANALYSIS OF FUSELAGE SKIN REPAIR JOINT
}

\section{Dr. S. SOLOMON RAJ ${ }^{1}$, Dr. G. LAXMAIAH ${ }^{1} \&$ V. RAVI KUMAR ${ }^{2}$}

${ }^{1}$ Department of Mechanical Engineering, Chaitanya Bharathi Institute of Technology, Hyderabad, Telangana, India

${ }^{2}$ M. Tech student, Chaitanya Bharathi Institute of Technology, Hyderabad, Telangana, India

In this paper, a dent occurred on a fuselage skin is considered, for which, a repair joint is designed using rivets and is analyzed for static and fatigue loads. Two dimensional model of a joint is taken and the load transfer through the joint is calculated using Patran and Nastran. Then, life of the joint is evaluated by carrying out the fatigue analysis in Ansys. The proposed joint is proved to be satisfactory as far as standards are concerned.

KEYWORDS: Fuselage Skin, Rivets, Patran \& Nastran
\end{abstract}

Received: Apr 02, 2019; Accepted: Apr 23, 2019; Published: May 17, 2019; Paper Id.: IJMPERDJUN201997

\section{INTRODUCTION}

Aircraft, subjected to structural repair / modification needs to be analyzed /evaluated to check the repair /modification in serving the adequate strength to resist the applied loads. The analysis uses static and dynamic loads, which causes fatigue in a structure. Here, a dent on a fuselage skin is analyzed and a repair joint is suggested using rivets. Riveted joints are often the most critical parts, with respect to fatigue life of structures. Therefore, it is important to analyze these components and the forces they are subjected to.

\subsection{Pressurization Cycles}

Commercial airplanes are pressurized to maintain the comfort level of passengers during flight. The fuselage skin behaves like a thin-walled pressure vessel, such as a balloon. The difference in pressure inside and outside the passenger cabin $(\Delta \mathrm{P})$ produces axial and radial tension loads. Membrane or hoop stresses result in the fuselage skin and curved bulkheads. Below figure 1, illustrates the effects of pressure $(\Delta \mathrm{P})$ on the fuselage skin.
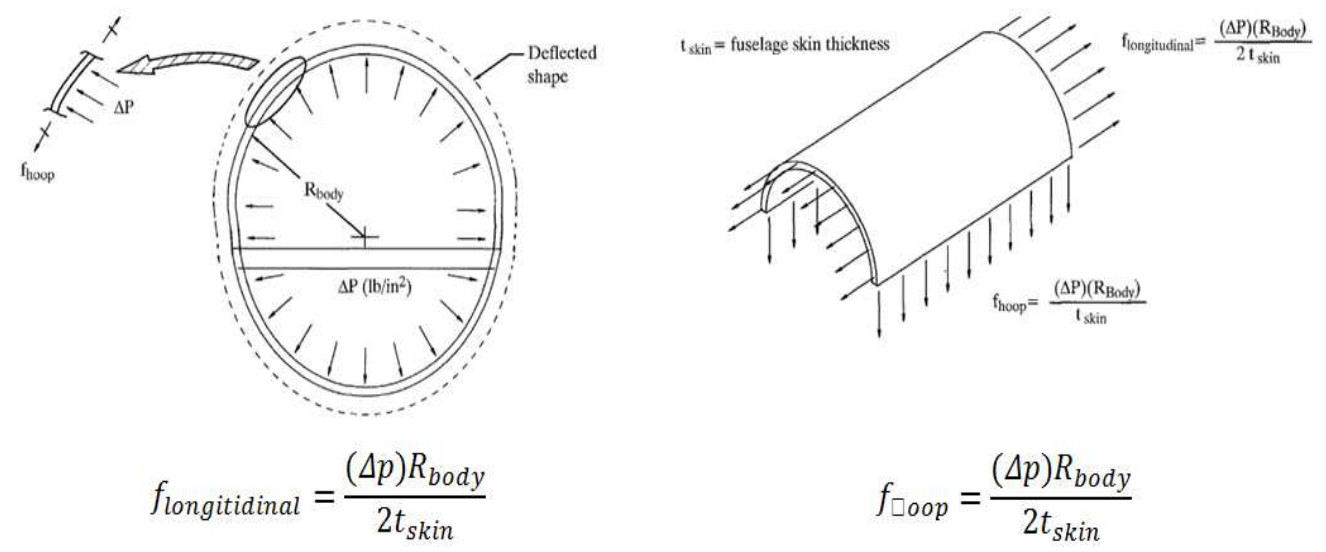

Figure 1: Effect of Pressure on Fuselage Skin 


\section{PROBLEM DESCRIPTION}

The damage considered here is only on skin, a dent. The dent was not reported in SRM or the dimensions might have been exceeding allowable limits. Therefore, a new repair configuration needs to be designed. Geometric details of damage, such as dent diameter and depth are shown in below figure 2.

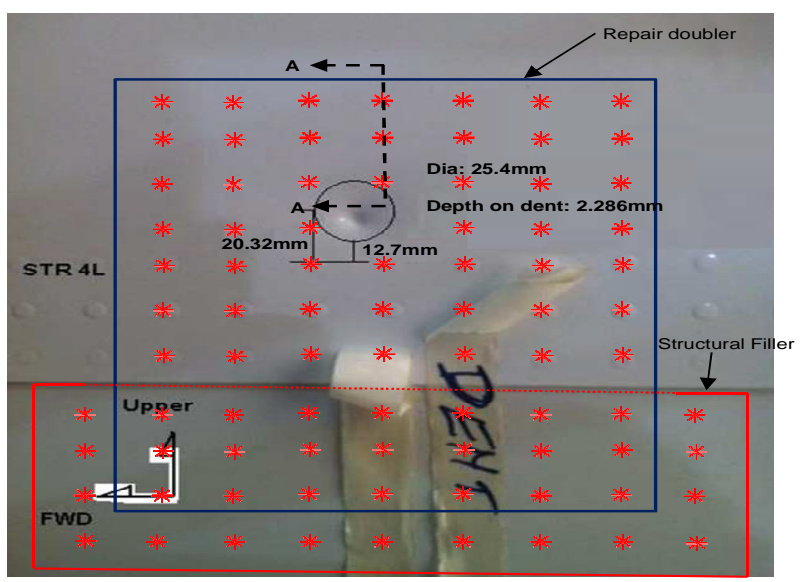

Figure 2: Dent on Fuselage Skin

\subsection{Material, Geometric and Mechanical Properties}

The material of the repair doubler and filler considered to be the same as to that of the baseline or primary structure, to avoid irregular load transfer. Since the load transfer is a function of flexibility, the less flexible is the more load carrying member and is not regular in transferring the load. The material properties of skin, doubler and structural filler are presented in the below given table 1.

Table 1: Material Properties

\begin{tabular}{|c|c|c|c|c|c|c|}
\hline S. No & part & Thickness/dia $(\mathbf{m m})$ & Material & E & Syt & Sut \\
\hline 1 & Fuselage & 1.016 & Al2024-T3 clad sheet & 73.1 & 270 & 405 \\
\hline 2 & Repair Doubler & 1.6002 & Al2024-T3 clad sheet & 73.1 & 275 & 420 \\
\hline 3 & Structural Filler & 1.6002 & Al2024-T3 clad sheet & 73.1 & 275 & 420 \\
\hline 4 & Fastener (MS20426-6D) & 9.525 & Al2017-T4 & 72.4 & -- & -- \\
\hline
\end{tabular}

\section{METHODOLOGY AND REPAIR ANALYSIS}

The dent identified on the center fuselage crown is having a dent depth greater than thickness; it is considered to be a major stress concentrated area, where a potential crack may start due to operating loads. Clearing the dent (sharp material elongation out of plane), i. e. flattening the dent parallel with skin may cause deformation. Therefore, clearing the dent in terms of trimming the elongated area has been proposed.

\subsection{Static Analysis}

The static analysis of the repair configuration gives the safety margin factor with respect to geometry and strength. The strength margin factor is calculated for doubler and the joint. In calculations, the actual loss of strength or required strength will be compared against the strength added in the form of doubler and the strength given to the joint with fasteners. The doubler is thicker and larger than the cut-out. The materials are same. The minimum margin safety factor 
is:GeomtericMarginof safety $=\frac{t_{\text {doubler }}}{t_{\text {skin }}}-1$, the margin of safety if greater than zero, which says the material loss, is restored and is ' $1+\mathrm{MS}$ ' times to the original thickness.Cross - sectionalarealossduetotrimout, $A_{\text {loss }}=D_{\text {trim }} * t_{\text {skin }}$. The circumferential or the hoop stress generated due to the internal pressure loading is calculated as follows.Circumferential/HoopStress, $f_{\text {hoop }}=\frac{P_{\text {diff } * R}}{t_{\text {skin }}}$, The strength loss or the strength to be restored due to trim out or area loss is $P_{\text {loss }}=f_{\text {hoop }} * A_{\text {loss. }}$. The joint strength can be calculated as JointStrnegth $=P_{\text {fastener-allowable }} *$ Numberoffasteners. The joint strength is compared against the strength loss which is to be restored and the margin of safety calculated as follows. Marginof safety $=\frac{\text { Jointstrength }}{P_{\text {loss }}}-1$. Therefore, the joint is having adequate strength to compensate the strength loss due to trim-out and it is structurally acceptable.

\subsection{Fatigue Analysis}

The fatigue analysis performed for the designed repair configuration, to know the number of flight cycles without having damage is generally known as threshold limit. The fatigue calculations performed herein, takes few points into account mentioned ref [1]: Severity factor (SF), which accounts for fastener type, method of installation, interference, hole preparation. detail design, fastener load distribution to avoid 'peaking effect', minimization of the stress concentration caused by both local load transfer at a fastener and bypass load, discrepancy factor, fatigue quality index, and finally fatigue life from S-N Curve.

\subsubsection{Severity Factor}

The severity factor (SF) as given by equations $1 \& 2$ is a fatigue factor that accounts for local peak stress caused by load transfer through fastener and by pass load transfer through plate.

$$
\begin{aligned}
& \mathrm{SF}=\frac{\alpha * \beta}{\alpha_{\mathrm{Ref}}} *\left(\sigma_{1}+\sigma_{2}\right) \\
& \sigma_{1}+\sigma_{2}=\frac{\mathrm{K}_{\mathrm{tb}} * \Delta \mathrm{P}}{\mathrm{Dt}} \theta+\frac{\mathrm{K}_{\mathrm{tg}} * \mathrm{P}}{\mathrm{Wt}}
\end{aligned}
$$

Where:

$\begin{array}{ll}\alpha & \text { - Surface Condition Factor } \\ \beta & \text { - Hole Filling factor } \\ \text { Ktb } & \text { - Bearing Stress Concentration Factor } \\ \text { Ktg } & \text { - Stress Concentration Factor } \\ \theta & \text { - Bearing distribution factor } \\ \text { D } & \text { - Diameter of the fastener } \\ \text { t } & \text { - Thickness of the skin } \\ \text { W } & \text { - Width of the plate } \\ \Delta \mathrm{P} & \text { - Load transfer through fastener } \\ \text { P } & \text { - Bypass Load. }\end{array}$




\subsubsection{Modeling of Joint}

In order to calculate the severity factor (SF), it is mandatory to know the load transfer through fastener. The load transfer through fastener has been calculated by modeling a flexible joint assembly including number of rows of fastener elements. The below figure 3 shows the creation of common 1D model used to calculate the fastener load transfer.

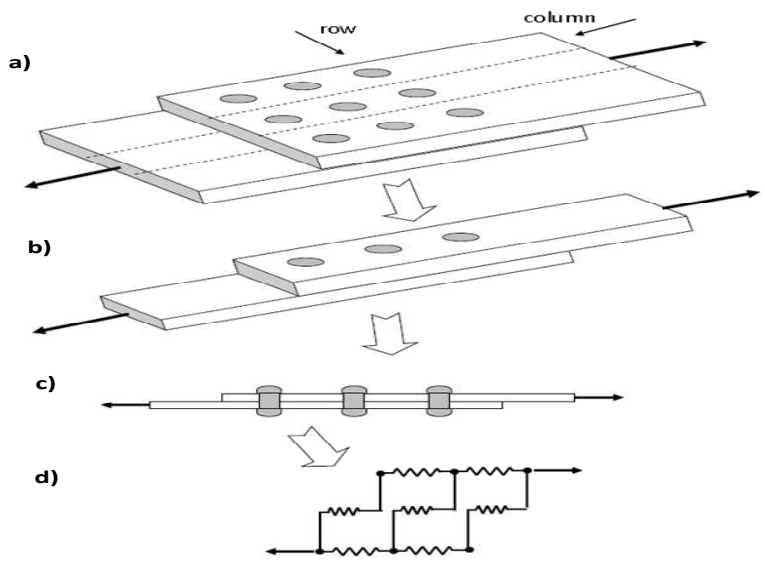

Figure 3: Idealization of Common 1D-Model of a Joint [2]

Though it is widely accepted to go with 1D model, the present analysis of calculating fastener loading factor uses 2D model. And, the creation of the 2D model has done using "Patran" and the calculations are processed in Nastran with finite element techniques. Using a two-dimensional model figure 4, one can take into account variations in bolt properties between fastener columns and handle situations where, for example, a large joint assembly has been reinforced at some point with additional plates and fasteners of different dimensions. This kind of model could also more accurately account for forces in the transverse direction, in cases where these are prominent.

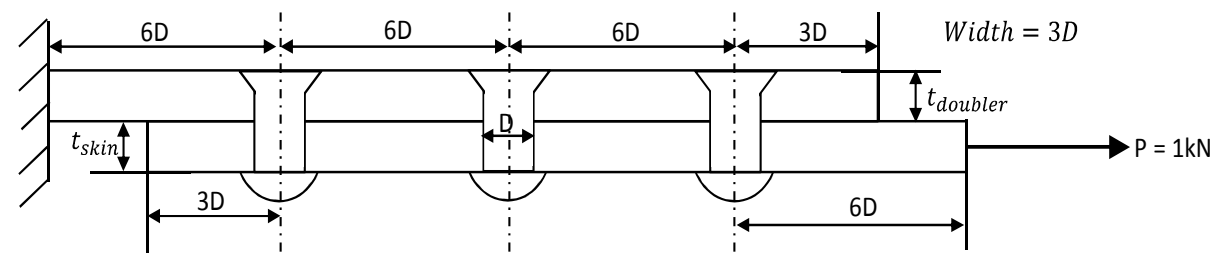

Figure 4: 2D joint Dimensions for Patran Modeling

The guideline of the model is that of the two-dimensional model. However, in order to be able to handle temperature variations and to spare the user from having to calculate the stiffness's in the joined elements (plates) and fasteners, the fasteners are modeled as bars. Since the plate is directly created and the real properties are assigned, no external stiffness calculation is required. Since the fastener is modeling as bar element, the fastener stiffness is calculated externally using "Huth" formula and supplied to Patran as a bar property. As seen, there are several ways to find the fastener flexibility experimentally. Many have attempted - via testing on geometries with varying parameters - to create methods for describing the joint behavior by calculating the fastener flexibility as a function of these parameters. These include, empirical formulas derived from specific types of joints and materials by Grumman [10], Huth [5], Boeing [10], Douglas [10], Tate \& Rosenfeld [6] and others, using an analytical approach such as methods by Barrois [3] and ESDU [4]. The great variety of available methods is due to the fact that they have been derived using different simplifications and/or that they apply to specific materials or specific types of joints. Based on extensive testing on different types of joints and 
materials, a formula for fastener flexibility was fitted to load-displacement curves as given by Huth is

$\mathrm{f}=\left(\frac{\mathrm{t}_{1}+\mathrm{t}_{2}}{2 \mathrm{~d}}\right)^{\mathrm{a}} * \frac{\mathrm{b}}{\mathrm{n}} *\left(\frac{1}{\mathrm{t}_{1} \mathrm{E}_{1}}+\frac{1}{\mathrm{nt}_{2} \mathrm{E}_{2}}+\frac{1}{2 \mathrm{t}_{1} \mathrm{E}_{\mathrm{f}}}+\frac{1}{2 \mathrm{nt}_{2} \mathrm{E}_{\mathrm{f}}}\right)$

$\mathrm{t}_{1}=$ Thickness of primary plate

$\mathrm{t}_{2}=$ Thickness of secondary plate

$\mathrm{E}_{1}=73100 \mathrm{Mpa}$ (modulus of elasticity of Primary Plate)

$\mathrm{E}_{2}=73100 \mathrm{Mpa}$ (modulus of elasticity of secondary Plate)

$E_{f}=72400 \mathrm{Mpa}$ (modulus of elasticity of Primary Plate)

$\mathrm{a}=0.4$ (for riveted metallic joints),

$b=2.2$ (for riveted metallic joints),

$\mathrm{n}=1$ (for single lap shear),

$\mathrm{d}=$ Diameter of the fastener

The $2 \mathrm{D}$ joint is created in patron with the dimensions mentioned above. The material and their properties are assigned accordingly for the skin, doubler and fasteners. The boundary conditions are also assigned. A. bdf file so created is processed in Nastran. The maximum resulting fastener load is as shown in figure 5. The maximum load taken by the fastener is $398 \mathrm{~N}$, and the corresponding loading factor is $0.398 \mathrm{P}$.

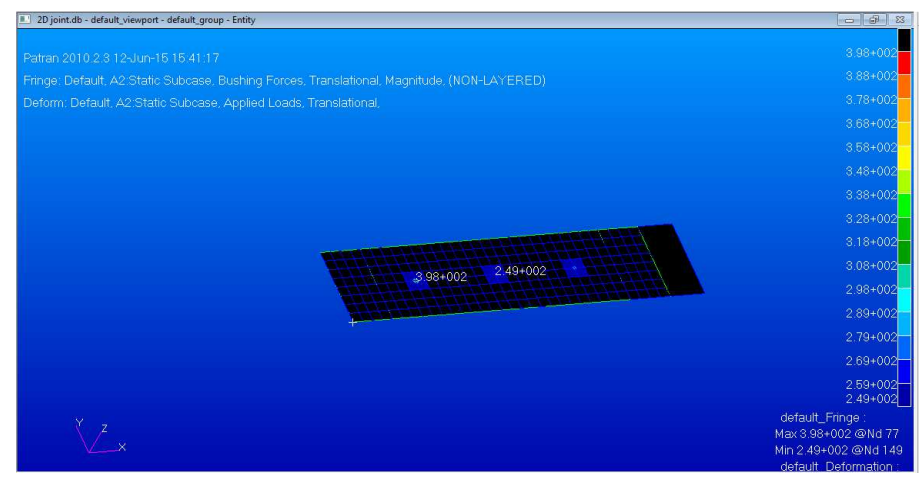

Figure 5: Load on the Fastener

\section{RESULTS AND DISCUSSIONS}

\subsection{Static Analysis}

The geometric margin of safety is calculated for different fastener diameters, doubler thicknesses and skin thicknesses are as shown in table 2 .

Table 2: Geometric Margin of Safety

\begin{tabular}{|c|c|c|c|c|c|}
\hline $\begin{array}{c}\text { S. } \\
\text { No. }\end{array}$ & $\begin{array}{c}\text { Fastener } \\
\text { Diameter } \\
(\mathbf{m m})\end{array}$ & $\begin{array}{c}\text { Fastener } \\
\text { Allowable } \\
\text { Strength }(\mathbf{N})\end{array}$ & $\begin{array}{c}\text { Doubler } \\
\text { Thickness } \\
(\mathbf{m m})\end{array}$ & $\begin{array}{c}\text { Skin } \\
\text { Thickness } \\
(\mathbf{m m})\end{array}$ & $\begin{array}{c}\text { Geometric } \\
\text { Margin of } \\
\text { Safety }\end{array}$ \\
\hline 1 & 3.97 & 3283.9 & 1.27 & 1.016 & 0.25 \\
\hline 2 & 4.7625 & 4027.02 & 1.6002 & 1.016 & 0.575 \\
\hline 3 & 6.35 & 3760.03 & 1.8034 & 1.016 & 0.775 \\
\hline
\end{tabular}


From the above table, Geometric Margin of Safety value 0.575 is acceptable, the reasons are: Geometric Margin of Safety value 0.25 has corresponding doubler thickness, has $1.27 \mathrm{~mm}$. The thickness of doubler can be one grade more than the thickness of the fuselage skin $(1.016 \mathrm{~mm})$. Hence, the geometric margin of safety 0.25 is not acceptable. The Geometric Margin of Safety value 0.775 has corresponding doubler thickness value $1.8034 \mathrm{~mm}$ and fastener diameter value $6.35 \mathrm{~mm}$. So, because of these, the weight of joint will increases, which is undesirable. Hence, geometric margin of safety 0.775 is not acceptable. The joint having strength $4027.02 \mathrm{~N}$ is chosen as higher strength is preferable. The table 3 shows the variation of hoop stress as a function of pressure difference.

Table 3: Variation of Hoop Stress as a Function of Pressure Difference

\begin{tabular}{|c|c|c|c|c|}
\hline S. No & $\begin{array}{c}\text { Radius of } \\
\text { Fuselage } \\
(\mathbf{m m})\end{array}$ & $\begin{array}{c}\text { Pressure } \\
\text { Difference } \\
(\mathbf{M P a})\end{array}$ & $\begin{array}{c}\text { Skin } \\
\text { Thickness } \\
(\mathbf{m m})\end{array}$ & $\begin{array}{c}\text { Hoop } \\
\text { Stress } \\
(\mathbf{M p a})\end{array}$ \\
\hline 1 & 1879.6 & 0.05136 & 1.016 & 95.016 \\
\hline 2 & 1879.6 & 0.05377 & 1.016 & 99.4745 \\
\hline 3 & 1879.6 & 0.05757 & 1.016 & 106.5045 \\
\hline
\end{tabular}

From the above table the maximum hoop stress $106.5045 \mathrm{MPa}$ is acceptable the reason is that: If the fuselage skin is bearing the maximum hoop stress then it is applicable for lower pressures also and flight life cycles calculated based on the maximum hoop stress. The corresponding pressure difference value $0.5757 \mathrm{MPa}$ is acceptable.

\subsection{Fatigue Analysis}

The fatigue analysis is carried out to find out the number of flight cycles, the fuselage skin repair joint can sustain. The loading cycle is as shown below figure 6 .

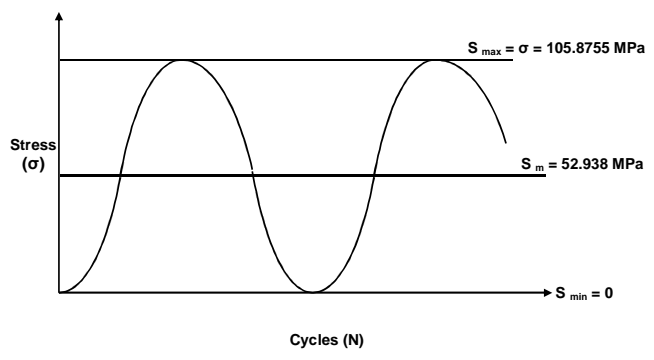

Figure 6: Load Cycle on Joint

The calculated Kth, Ktg and theta are as shown in following table 4.

Table 4: Kth, Ktg and Theta

\begin{tabular}{|c|c|c|c|c|c|c|c|c|c|c|}
\hline $\begin{array}{c}\text { S. } \\
\text { No. }\end{array}$ & $\begin{array}{c}\text { Width } \\
\text { of Plate, } \\
\mathbf{W} \\
(\mathbf{m m})\end{array}$ & $\begin{array}{c}\text { Fastener } \\
\text { Radius, } \\
(\mathbf{m m})\end{array}$ & $\begin{array}{c}\text { Edge } \\
\text { Distance, } \\
\mathbf{C}(\mathbf{m m})\end{array}$ & $\begin{array}{c}\text { Thickness of } \\
\text { Skin, t }(\mathbf{m m})\end{array}$ & $\mathbf{D} / \mathbf{W}$ & $\mathbf{K}_{\text {tb }}$ & $\mathbf{r} / \mathbf{C}$ & $\mathbf{K}_{\text {tg }}$ & $\mathbf{t}$ & $\mathbf{\theta}$ \\
\hline 1 & 23.82 & 1.985 & 13.895 & 1.016 & 0.167 & 1.2 & 0.143 & 3 & 0.256 & 1.12 \\
\hline 2 & 28.575 & 2.38125 & 16.66875 & 1.016 & 0.167 & 1.2 & 0.143 & 3 & 0.213 & 1.25 \\
\hline 3 & 38.1 & 3.175 & 22.225 & 1.016 & 0.167 & 1.2 & 0.143 & 3 & 0.16 & 1.32 \\
\hline
\end{tabular}

The flexibility and stiffness of the joint are calculated and presented in figure 7 . The fatigue life and the safety factors as evaluated from the Ansys are presented in figure 8. 

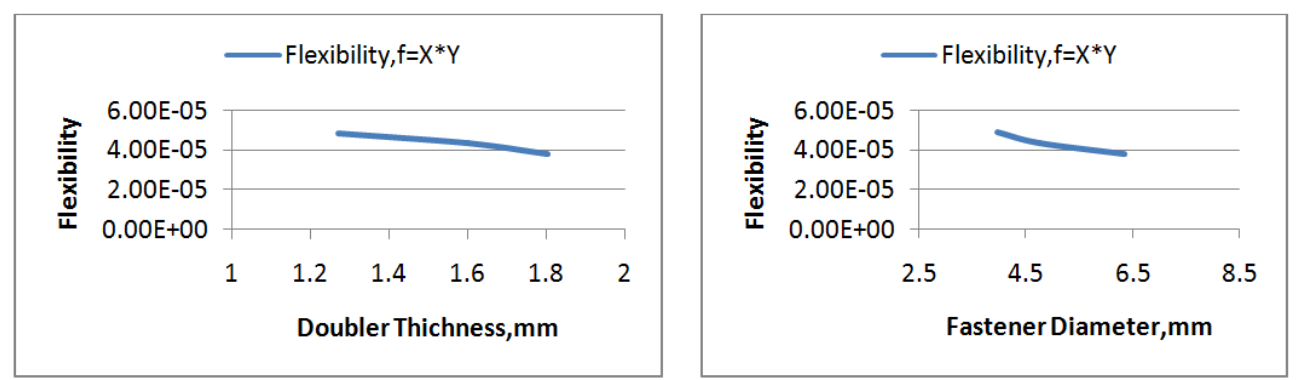

Figure 7: Flexibility Variation
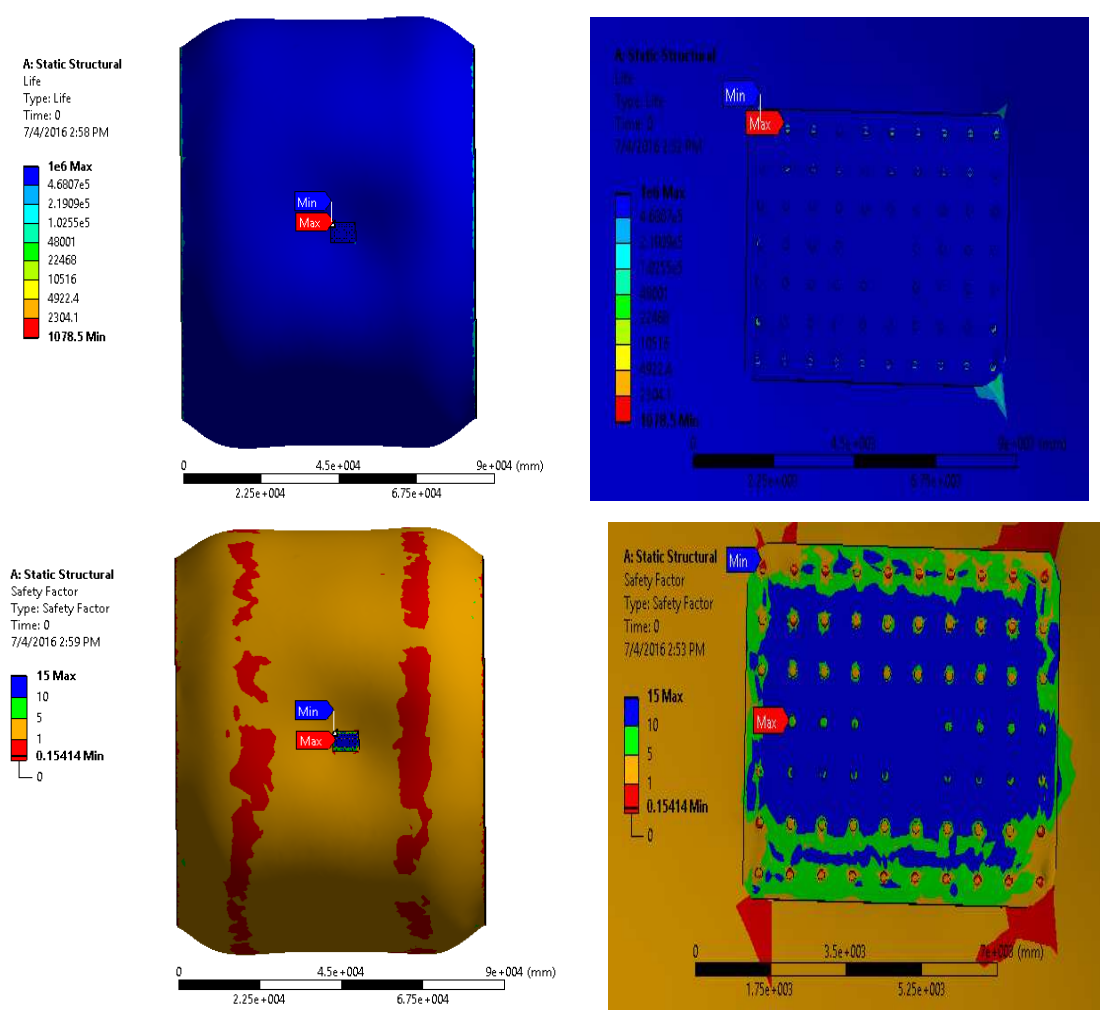

Figure 8: Life and Safety Factor as Evaluated through ANSYS

\section{CONCLUSIONS}

A joint is proposed for a damaged fuselage skin in terms of doubler thickness, no of rows of rivets, and filler. The margin of safety is greater than zero to make the joint statically viable. The load carrying capacity of the joint is calculated as $12081 \mathrm{~N}$, and maximum hoop stress as $106 \mathrm{Mpa}$. The life of the joint calculated is 72437 cycles, which is a reasonable life as far as aerospace components are concerned.

\section{REFERENCES}

1. Airframe Stress Analysis and sizing by “Michael Chun-Yung Niu”, Second Edition, Jan 1999.

2. A finite element method for calculating load distributions inbolted joint assemblies, LIU-IEI-TEK-A--12/01328|SE Saab report LN-003297.

3. W. Barrois. Stresses and displacements due to load transfer by fasteners in structural assemblies. Engineering Fracture Mechanics, 10(1):115\{176, 1978. 
4. ESDU. Flexibility of, and load distribution in, multi-bolt lap joints subjected to in-plane axial loads. Data item, Engineering Sciences Data Unit, 2001.

5. Al-Sharidi, S. H., Sitepu, H., \& AlYami, N. M. Application of Tungsten Oxide (WO3) Catalysts Loaded with Ru and Pt Metals to Remove MTBE from Contaminated Water: A Case Of Laboratory-Based Study. IMPACT: International Journal of Research in Engineering \& Technology, ISSN (P): 2347-4599; ISSN (E): 2321, 8843, 19-30.

6. H. Huth. Experimental determination of fastener exibilities. Report LBF-Bericht 4980, Fraunhofer-Institut fur Betriebsfestigkeit, Darmstadt, 1983.

7. H. Huth. Inuence of fastener exibility on the prediction of load transfer and fatigue life for multiple-row joints. Fatigue in Mechanically Fastened Composite and Metallic Joints, ASTM STP927, pages 221\{250, 1986.

8. L. Jarfall. Shear loaded fastener installations. Report KH R-3360, Saab-Scania, 1983. 